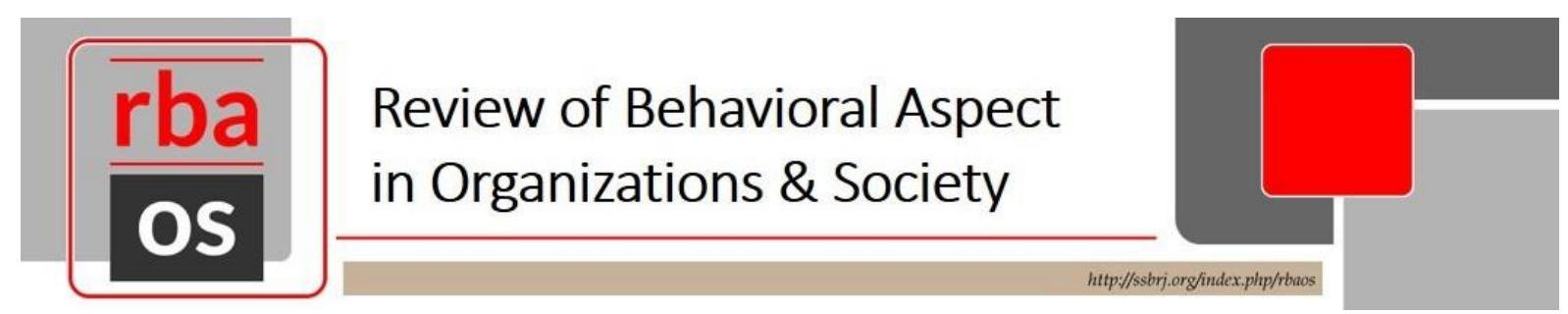

\title{
WEB USERS' ATTITUDE TOWARD POP-UP ADVERTISEMENTS IN WESTERN PROVINCE OF SRI LANKA
}

\author{
Ishara Madurangi Katuwandeniya, Sabaragamuwa University of Sri Lanka, Sri Lanka \\ Ashani Randi Shanika Abeywardana, Sabaragamuwa University of Sri Lanka, Sri

\section{Lanka}

\begin{abstract}
Advertisers have been able to expose to modern channels and modern platforms of advertising. This enables to create an immediate global presence and generate greater value to the companies. Among these modern platforms, the internet act as a communication medium that allows companies to create awareness, provide information, and influence others. Therefore companies increasingly saw the internet as an important medium through which advertising messages can be directed towards consumers. Using a self-administered questionnaire, a survey study was conducted, and data were collected from 360 university students of four major universities in Western Province. The findings of the study revealed that only entertaining and irritating factors impact on attitude toward pop-up ads. While entertaining factor positively impacts on attitude, irritating factor negatively impacted on the attitude towards pop-ups. Critical consideration by companies before choosing a pop-up as their advertising mode is needed as web users' negative attitude towards it can impact adversely. Further, it will be helpful for advertisers to create more attractive and user-friendly pop-up advertisements. Keywords: web users' attitude, web advertisements, pop-up ads
\end{abstract}




\section{Introduction}

Advertising is a paid form of non-personal communication to present and promote ideas, goods, or services by an identified sponsor (Kotler \& Keller, 2012). As the internet as a communication medium, allows companies to create awareness, provide information, and influence others. Hence companies increasingly see the internet as an important medium through which advertising messages can be directed towards consumers (Aziz \& Ariffin, 2010).

With the development of the technological era, doing business activities over the internet has grown rapidly. One of the popular business activities among them is web advertising. This promotional tool delivers advertising messages to masses by using a variety of media. Before the emergence of the internet, firms used traditional advertising media such as television, radio, or newspaper to reach the target audience, aware of the public about their products, and increase sales. Modern-day technology advancement has enabled modern channels and platforms for advertising, such as website advertising, email advertising, mobile advertising, and SMS advertising (Le \& Vo, 2017). When a user opens one of those web sites, a pop-up ad will appear automatically in a separate window on the top of the content the user is viewing and will stay on the screen until the user closes it. If the user clicks on the pop-up advertisement, it will navigate the user to a different web site. The pop-up window can contain advertising messages with games, graphics, animations, audio, or video. Pop-ups are designed to link with most frequently visited websites. The pop-up ad aims to divert the traffic to the desired web site (Kapesa, 2014).

As many researchers tend to assess the effectiveness of web advertisements by measuring web users' attitudes, behaviors, purchasing intentions, etc. Pop-up ads said to be irritating advertisement types compared to other advertising formats. Researchers also added that users only focus on the close button of the pop-up window, not the advertise massage. Although some pop-up ads contain the option to close the ad by closing the pop-up window, newer ad formats do not offer such an opportunity. Web users are forced to view advertisements if they do not wish to see the content of the web site.

The researcher employed an extension of the web advertising model, which has been tested in many contexts. It is estimated that the number of people assessing the internet grew by $1104 \%$ worldwide between 2000 and 2019. This emphasis that online browsing has become part of an individual's day to day activities. As stated by Wang, Ampiah, Xu \& Wang (2014), several hours are spent by people to access content on the internet daily. This is a motive for businesses to engage in online advertising to reach for customers. However, the real question they should answer is "what would happen when a pop-up ad comes on the screen covering all or half of the content user viewing?"

Many researchers have shown a negative attitude towards this incident, and they have introduced many factors within the past few years. Most of them were conducted in developed countries such as the UK or USA, where advertising technologies are advanced, and it shows that consumers have different perceptions about an online advertisement (Wang \& Sun, 2010).

Hence in Sri Lankan context, the preliminary survey outcomes show, web users had developed a negative attitude towards pop-up advertisements. Further, to identify what are the factors 
affecting that particular attitude researcher raised the question, "Why there is a negative attitude toward pop-up advertisements among undergraduates in Western Province?"

\section{Undergraduates 'attitude towards the pop-up advertisement}

Web users' attitudes towards online advertising can be express as web users' favorable or unfavorable responses towards particular online advertisement (MacKenzie \& Lutz, 1989). Overall evaluation expresses the extent of favor or disfavor of an individual towards an object, issue, person, or action, and it tends to be a continuing emotional feeling. (Chan, Chee, Chin \& Sim, 2014). A study done by McCoy et al. (2004), in the US and Mexican contexts, stated that users would adopt more negative behaviors when a site displays ads. Pop-up and in-line ads are rectangular shape ads which can be seen beside or inside the main content of the web page. Attitude towards such ads differs from context to context. This study focuses on three variable that impacts on the attitude

\section{Informative}

Informative means that the ability of advertising to inform consumers about the product alternatives, and by considering that, the consumer can make purchasing decisions (Schlosser et al., 1999). According to Ducoffe (1996), information is vital to forecast the advertising value and critical in evaluating the impact of advertisements on the consumer. Cheng, Blankson, Wang, \& Chen, (2009) stated that consumer's attitude has a significant impact on an ad's informative capability.

\section{Entertaining}

Entertaining refers to an advertisement's ability to fulfil audience requirements for aesthetic enjoyment or emotional release (Ducoffe, 1996). Ducoffe (1996) stated that entertainment has a direct association with the attitude towards web advertising. According to Wang \& Sun (2010), Entertainment is an essential component that influences the effectiveness of advertising. Also, Jung, Shim, Jin, \& Khang (2016) stated that entertainment was a significant predictor of attitude.

\section{Irritating}

Irritating refers to disturbing tactics used by advertisers in advertisements that annoy and distract web users when they are surfing the internet (Li et al., 2002). User will feel irritated when advertisement content deliver false information or confusing information (Cheng et al., 2009). Researchers who focus on the web user's attitude towards web advertisement found out that irritation has a negative impact on attitude (Tsang et al., 2004). According to Le \& Vo (2017), web users perceive pop-up ads as confusing, deceptive, and annoying.

To illustrate the attitude towards pop up ads, the researcher selected undergraduates of four main universities within the western province as the sample. Hence, the research sites cover western province leading universities. According to Wang \& Sun (2010), the primary reason for using a university student sample is based on the assumption that they have easy access to the internet and hence are more likely to be exposed to online advertising. Further, Le and Vo (2017) stated that young people probably spend more time on the internet and have the ability to understand the new display advertising concepts rather than older people.

Following a positivist philosophy researcher developed a hypothesis based on previous studies and developed a conclusion that can be generalized to the undergraduate population, the researcher uses the deductive approach to conduct the research, and the study was an explanatory one which explains the relationship between three variables and the attitude. To 
collect data for this study, the researcher used structured questionnaires. Out of 384 questionnaires, 317 questionnaires were collected. Multiple regression analysis was used to address the research questions of the study.

\section{Findings and Discussion}

The present study was conducted to investigate the factors impact on undergraduates' attitudes towards pop-up advertisements in the western province.

The demographic composition of respondents

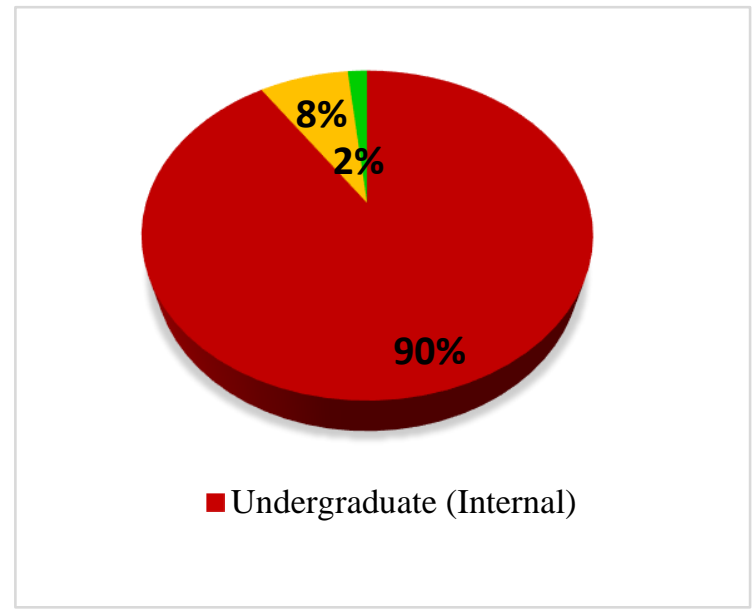

Figure 01. Educational Level

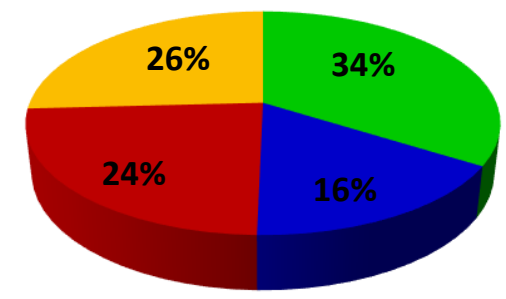

Entertainment

- Information \& News

- Study Purpose

Social Media

Figure 02. Purpose of using the internet 


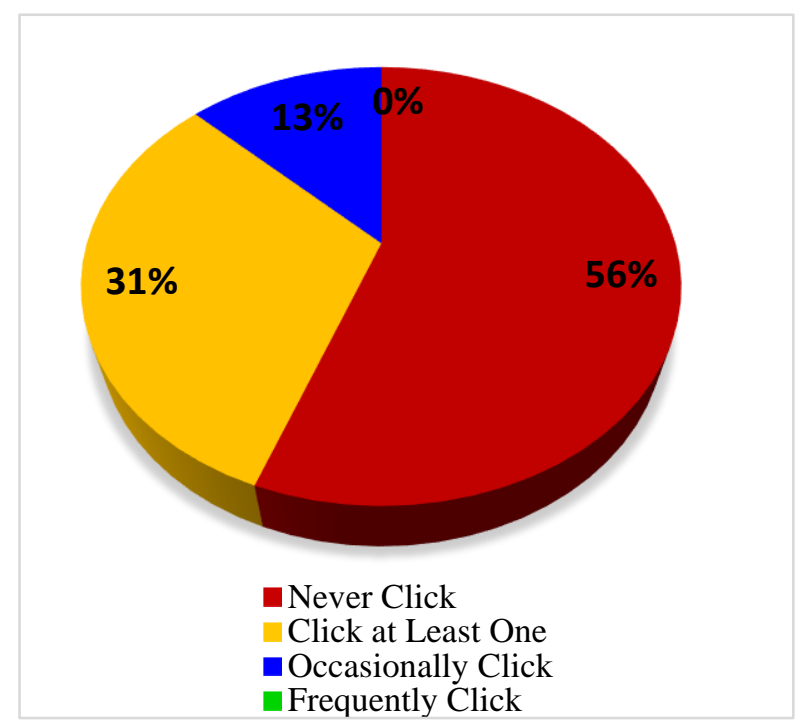

Figure 03. Response to pop up ad.

It was revealed through the findings that only entertaining and irritating have an impact on attitude towards the pop-up advertisement although the researcher argued that informative impact on attitude towards pop-up advertisement, it was found that there was no impact from informative in the selected context.

According to Table 1, attitude toward pop-up ads shows the lowest mean value (2.2836). This depicts that the attitude towards pop-up ads in the western province is not at a higher level. The standard deviation of 0.56530 shows the deviation range. Entertaining has the lowest mean value of (2.4493) among three independent variables with a standard deviation of 0.70182 . In addition to that Informative and Irritating have the mean values of 2.4583 and 3.9188 respectively with standard deviations of 0.79874 and 0.87232

Table 1. Descriptive Statistics

\begin{tabular}{ccc}
\hline Variable & Mean & Standard Deviation \\
\hline Attitude towards pop-up ads & 2.2836 & 0.56530 \\
Informative & 2.4583 & 0.79874 \\
Entertaining & 2.4493 & 0.70182 \\
Irritating & 3.9188 & 0.87232 \\
\hline
\end{tabular}

Source: (Survey data, 2019)

Results of correlation analysis showed that attitude towards pop-ups have a strong positive correlation in informative and entertaining while irritating has a high negative correlation. According to the finding, it is relieved that entertainment has a positive impact on attitude and irritation hurts attitude towards pop-up ads while there is no impact of informative on attitude towards pop-up ads.

Table 2. Results of Correlation Analysis 


\begin{tabular}{|c|c|c|c|c|c|}
\hline $\begin{array}{l}\text { Dependent } \\
\text { Variable }\end{array}$ & & $\begin{array}{c}\text { Attitude } \\
\text { towards } \\
\text { pop-up ads }\end{array}$ & Informative & Entertaining & Irritating \\
\hline \multirow{2}{*}{$\begin{array}{c}\text { Attitude } \\
\text { towards } \\
\text { pop-up ads }\end{array}$} & $\begin{array}{c}\text { Pearson } \\
\text { Correlation }\end{array}$ & & 0.771 & 0.811 & -0.858 \\
\hline & $\mathrm{P}$ value & & 0.000 & 0.000 & 0.000 \\
\hline \multirow{2}{*}{ Informative } & $\begin{array}{c}\text { Pearson } \\
\text { Correlation }\end{array}$ & & - & 0.877 & -0.849 \\
\hline & P-value & & - & 0.000 & 0.000 \\
\hline \multirow{2}{*}{ Entertaining } & $\begin{array}{c}\text { Pearson } \\
\text { Correlation }\end{array}$ & & - & - & -0.845 \\
\hline & P-value & & - & - & 0.000 \\
\hline
\end{tabular}

Source: (Survey data, 2019)

Hypothesis testing of the study

$\mathrm{H}_{1 \mathrm{~A}}$ : There is an impact of Informative on undergraduates' attitude towards pop-up advertisement in Western Province.

Since the P-value of the Informative (0.687) is higher than the critical value 0.05 , there is no enough evidence to reject HOA (There is no impact of informative on attitude towards pop-up advertisement in Western Province). Therefore, it can be concluded that there is no impact of informative on attitude towards pop-up advertisement in Western Province under a 95\% confidence level.

$\mathrm{H}_{1 \mathrm{~B}}$ : There is an impact of Entertaining on undergraduates' attitudes towards pop-up advertisement in Western Province.

Since the P-value of the Entertaining (0.000) is less than the critical point 0.05, there is enough evidence to reject H0B (There is no impact of Entertaining on undergraduates' attitude towards pop-up advertisement in Western Province). Therefore, it can be concluded that there is an impact of entertaining undergraduates' attitudes towards pop-up advertisement in Western Province under a $95 \%$ confidence.

$\mathrm{H}_{1 \mathrm{C}}$ : There is an impact of Irritating on undergraduates' attitude toward the pop-up advertisement in Western Province.

Since the P-value of Irritating (0.000) is less than the critical point 0.05 , there is enough evidence to reject H0C (There is the impact of Irritating on undergraduates' attitude toward pop-up advertisement in Western Province). Therefore, it can be concluded with 95\% confidence that there is an impact of Irritating on undergraduates' attitude toward pop-up advertisement in Western Province.

The study illustrates that informative has no impact on attitude towards pop-up ads. This finding goes against most of the findings of the past researches. Informativeness said to be one of the main attributes, which shows the highest variance in the study of Cheng et al. (2009). According to Ha et al. (2014), informativeness had a significant influence on attitude, but it is not statistically supported to purchase intention. Moreover, Mahmoud (2014) stated a similar 
statement as information factor show favorable believes, and attitude towards web advertising, and it will indirectly make web users like web advertisements.

Even though informative is significant in another context, there can be reasons to get insignificant in this context. The researcher believes that with the highest negative impact that occurred by irritation, web users may refuse to even look at the content of the pop-up ad. Hence, the customer pays very little attention to the informative factor of the ad. This is proven by the sample profile analysis, and it showed that the respondent's purpose of using the internet for information and news is at a lower level (16\%). Another reason is that most of the pop-up ads are advertised by foreign ads from foreign countries. If the ad is from the local advertiser, the web user may read the information of the ad. Since it is not, users neglect the information contain in the ad.

Entertaining shows a positive impact on attitude towards a pop-up ad in the current study. These findings confirmed by past scholars in many contexts. Entertainment can be identified as the most important construct that explains attitude (Ha et al., 2014). It is also empirically proven in the study of (Ducoffe, 1996). The results of Yang et al. (2017), shows that entertainment has a strong explanatory effect on attitude. In the words of Jung et al. (2016), entertainment was a significant predictor of attitude. Several research findings are tallying with the present research finding of the positive impact of entertaining on web users 'attitudes towards.

In the results of the current study, irritation shows a negative impact on undergraduates' attitudes towards pop-up advertisements. Irritation found to have a negative effect on attitude in previous studies as well (Tsang et al., 2004; Yang et al., 2017). According to Le \& Vo (2017), web users perceive pop-up ads as confusing, deceptive, and annoying. Further, Mahmoud (2014), explains that some advertisements contained inappropriate content that makes young consumers mislead. These factors may affect to build a negative impact on attitude.

\section{Conclusion}

This study aims to identify the factors affecting a negative attitude towards pop-up advertisements in the western province. Since most population lies in the western province and the highest number of web users are in the western province, researcher select western province undergraduates to conduct the study. The researcher selected a commonly used web advertising scale to measure the impact of informative, entertaining, and irritating attitudes towards the pop-up advertisement.

According to the key findings based on the analysis, it reveals that entertainment has a positive impact on attitude, and irritation has a negative impact on attitude towards pop-up ads while there is no impact of informative on attitude towards pop-up ads.

This study will provide the groundwork for advertisers to understand undergraduates' attitudes towards pop-up ads to create effective advertising. That will also help in designing web userfriendly pop-up ads so that users may do not feel pop-ups as intrusive. Advertisers need to focus on factors influencing negative attitudes toward pop-ups and try to eliminate or reduce them.

To avoid the irritating factor of the pop-ups, advertising firms can reduce full-screen pop-ups that hide all the content user viewing and display the close button clearly and remove any 
hyperlinks attached to it. To upturn the entertaining factor of pop-ups and increase the attitude toward it, advertising firms can add more attractive graphics, music, and animations to popups. Results obtained from this study will help companies to make important decisions in allocating funds for pop-ups. For the reason that those companies spend considerable money on pop-ups, it is vital to know whether they can attract the target market or not. They also need to understand to what extent pop-ups affect customer purchasing behavior.

There is several questions that need to be answered and deserve future investigations. The researcher believes that it is important to study this topic further by considering other provinces, other categories in the population. It is better to focus on other forms of online advertisements also since web users may have a different attitude towards them. Moreover, studies can be conducted to examine not only the attitude but also the behavior and purchasing intention.

\section{References}

Aziz, N. A., \& Ariffin, A. A. (2010). Exploring consumers attitude towards web advertising and its influence on web ad usage in Malaysia. journal Pengurusan, 31, 55-63.

Cheng, J. M.-S., Blankson, C., Wang, E. S.-T., \& Chen, L. S.-l. (2009). Consumer attitudes and interactive digital advertising. International Journal of Advertising: The Review of Marketing Communications, 28(3), 501-525.

Ducoffe, R. H. (1996). Advertising value and advertising on the web. Journal of Advertising Research, 36(5), 21-35.

Ha, Y. W., Park , M.-C., \& Lee , E. (2014). A framework for mobile SNS advertising effectiveness: user perceptions and behaviour perspective. Behaviour \& Information Technology, 33(12), 1333-1346.

Jung, J., Shim, S. W., Jin, S. H., \& Khang, H. (2016). Factors affecting attitudes and behavioural intention towards social networking advertising: a case of Facebook users in South Korea. International Journal of Advertising, 35(2), 248-265.

Kapesa, D. L. (2014). Green Firm's Use of Pop-Ups and In-Line Ads to Affect Consumer Attitude. National Chung Hsing University.

Kotler, P., \& Keller, K. L. (2012). Marketing Management. $14^{\text {th }}$ ed. Pearson Education Inc.

Le, T. D., \& Vo, H. (2017). Consumer attitude towards website advertising formats: a comparative study of banner, pop-up and in-line display advertisements. International Journal of Internet Marketing and Advertising, 11(3), 202-217.

Chan, M. L., Chee, H. L., Chin, S. P., \& Sim, G. X. (2014). Consumers' attitude towards online advertising: the study on information responses. Doctoral dissertation, UTAR.

Li, H., Edwards, S. M., \& Lee , J. H. (2002). Measuring the Intrusiveness of Advertisements: Scale Development and Validation. Journal of Advertising, 31(2), 37-47.

MacKenzie, S. B., \& Lutz, R. J. (1989). An empirical examination of the structural antecedents of attitude toward the ad in an advertising pretesting context. Journal of marketing, 53(2), 48-65.

Mahmoud, A. B. (2014). Linking information motivation to attitudes towards web advertising. Journal of Islamic Marketing, 5(3), 396-413.

McCoy, S., Everard, A., Galletta, D., \& Polak, P. (2004). A Study of the effects of online advertising: A focus on pop-up and in-line ads. SIGHCI 2004 Proceedings, 50-54. Retrieved from http://aisel.aisnet.org/sighci2004/11

Schlosser, A. E., Shavitt, S., \& Kanfer, A. (1999). Survey of internet users' attitudes toward internet advertising. Journal of Interactive Marketing, 13(3), 34-54.

Tsang, M. M., Ho, S. C., \& Liang, T. P. (2004). Consumer attitudes toward mobile advertising: An empirical study. International journal of electronic commerce, 8(3), 65-78. 
Wang, L., Ampiah, F., Xu, L., \& Wang, X. (2014, November). The influence of pop-up advertising on consumer purchasing behavior. In 2014 International Conference on Mechatronics, Electronic, Industrial and Control Engineering (MEIC-14), 217-220. Atlantis Press.

Wang, Y., \& Sun, S. (2010). Examining the role of beliefs and attitudes in online advertising: A comparison between the USA and Romania. International Marketing Review, 27(1), 87-107.

Yang, K.-C., Huang, C.-H., Yang, C., \& Yang, S. Y. (2017). Consumer attitudes toward online video advertisement: YouTube as a platform. Kybernetes, 46(5), 840-853. 
